\title{
Spontaneous infarction of superficial lymph nodes
}

\author{
J. DOUGLAS DAVIES AND A. G. STANSFELD ${ }^{1}$
}

From the Department of Histopathology, St Bartholomew's Hospital, London

SYNOPSIS Five cases of extensive infarction of lymph nodes were traced in just over 16 years' surgical material. All presented with painful swelling in a superficial lymph node chain. None was diagnosed clinically; two were interpreted as fibroadenoma of the axillary tail of the breast, and two as a femoral hernia. Microscopically the lymph nodes in the first three weeks after infarction were characterized by extensive necrosis of medullary and cortical lymphoid cells, but the central reticulin architecture and a narrow, incomplete rim of viable subcapsular lymphoid tissue were preserved. Reactive perinodal inflammation and the formation of granulation tissue resembled the reaction to myocardial infarction. The late stage of the lesion was characterized by incomplete regeneration of lymphoid tissue in the lymph nodes. The lesions appeared attributable to thrombosis of veins within the substance and the hila of the nodes.

Though experimental infarction of lymph nodes has been produced in dogs (Holman and Self, 1938; Tilak and Howard, 1964; Kister, Conklin, and Habif, 1965) and rabbits (Osogoe and Courtice, 1968), spontaneous infarction of previously normal lymph nodes in man has rarely been recorded (Holman and Self, 1938). However, such infarction of lymph nodes may be commoner than is generally appreciated as four cases were found on review of surgical material received in one department in the last 16 years, and the fifth was received during the preparation of the manuscript of this paper. The clinical features and microscopic findings of the five cases are described, and the pathogenesis of the lesions and their morphological evolution are considered.

\section{Material and Methods}

Sections of lymph nodes classified as showing necrosis, calcification, circulatory disturbances, and necrotizing inflammation, received between January 1956 and January 1972 in the Department of Histopathology, St Bartholomew's Hospital, were reviewed. Excluded from further consideration were necroses associated with specific infections, druginduced hypersensitivity reactions, lymphomata, and metastatic tumours. From the paraffin blocks of those cases selected for further study additional sections were cut at a nominal depth of $5 \mu \mathrm{m}$. These

'Present address: Department of Pathology, University of Bristol, Bristol BS8 1TD. Requests for reprints should be addressed there. Received for publication 4 May 1972. were stained by Harris' haematoxylin and eosin, and Gordon and Sweet's method for reticulin. When appropriate PAS, Gram, or Ziehl-Neelsen preparations were examined.

\section{Case Reports}

The cases are presented in ascending order of histological maturity. In none of the cases were causative microorganisms detected.

\section{CASE 1}

A 43-year-old woman with a six-month history of a lump in the left breast was submitted to mastectomy and axillary clearance for an infiltrating ductal adenocarcinoma of the breast. All 10 lymph nodes from the left axilla were free of necrosis and metastasis. Postoperative irradiation was not given, but 11 days after the mastectomy she complained of a painful lump in the right anterior triangle of the neck. Clinically the pain was attributed to tight bandaging. Three days later, at the time of bilateral oöphorectomy, the swollen nodes in the right anterior triangle were excised. Subsequently there were no further similar symptoms, but a second primary carcinoma in the right breast was detected 30 months later. Six months afterwards tumour recurred in the right chest wall.

\section{HISTOPATHOLOGY}

Seven lymph nodes (St. B.H. S.H. 3694/67), up to $0.8 \mathrm{~cm}$ long, were received from the right anterior triangle of the neck. Microscopically two of the 
nodes were almost entirely necrotic, and a third was partially necrosed. The remaining four nodes exhibited non-specific reactive enlargement of the follicular germinal centres and paracortical areas. In two instances there was fresh extravation of erythrocytes into the cortical and medullary lymph sinuses. None of the nodes contained secondary carcinoma.

The two extensively necrotic lymph nodes showed eosinophilic ghosts of lymphoid cells amidst a fibrinous exudate in cortex and medulla (Fig. 1). Only a few peripherally situated lymphoid follicles in these nodes retained stainable lymphoid cells. In the necroses the original reticulin architectural pattern was preserved (Fig. 2). The necrosis in the third node was similar but it was limited to one pole of the node.

A striking feature of the necrotic nodes was a corona comprising an exudate of polymorphonuclears and fibrin in the perinodal connective tissue.
This inflammatory reaction hugged the edge of the necrotic nodes and few polymorphonuclears had crossed the largely intact marginal sinuses to enter the necroses. Many extranodal veins and lymphatic vessels were cuffed by a mixed inflammatory infiltrate comprising neutrophil and eosinophil granulocytes, lymphocytes, histiocytes, and a few plasma cells. Numerous small intranodal veins and several extranodal veins (Fig. 3 ) and lymphatic vessels contained fresh occlusive thrombi.

\section{CASE 2}

A 52-year-old woman presented with a three-day history of a painful lump in the axillary tail of the right breast. Other axillary lymph nodes were not palpable. Her general health had previously been good and she was not receiving any drugs. Sixteen days after the onset of symptoms the presumptive fibroadenoma in the axillary tail was excised and on rapid frozen section shown to be a necrotic lymph

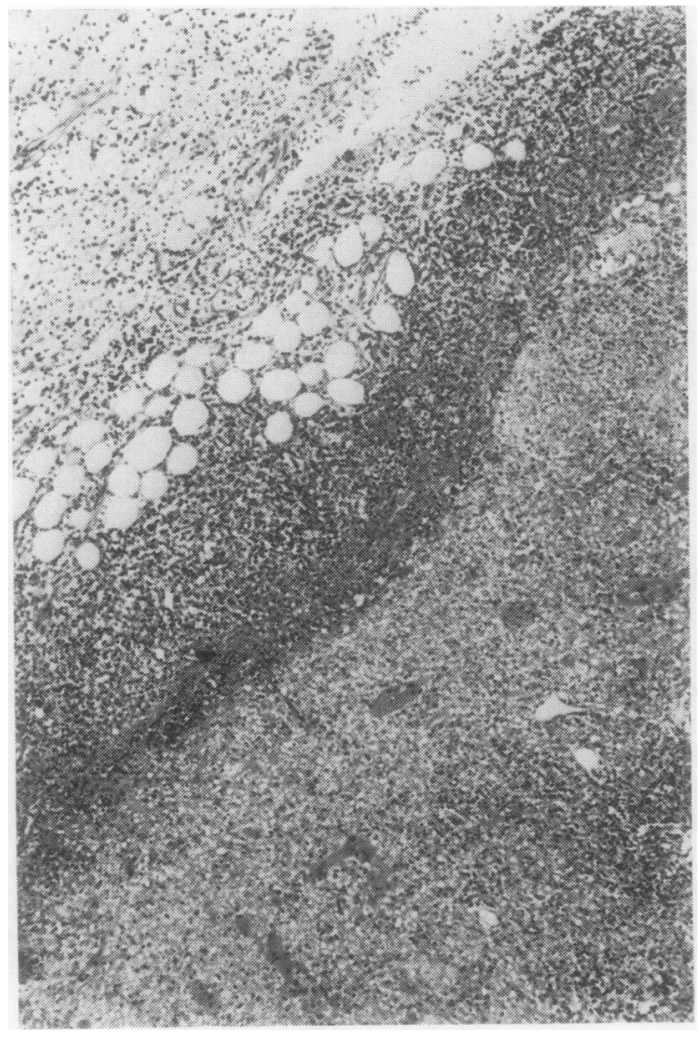

FIG. 1

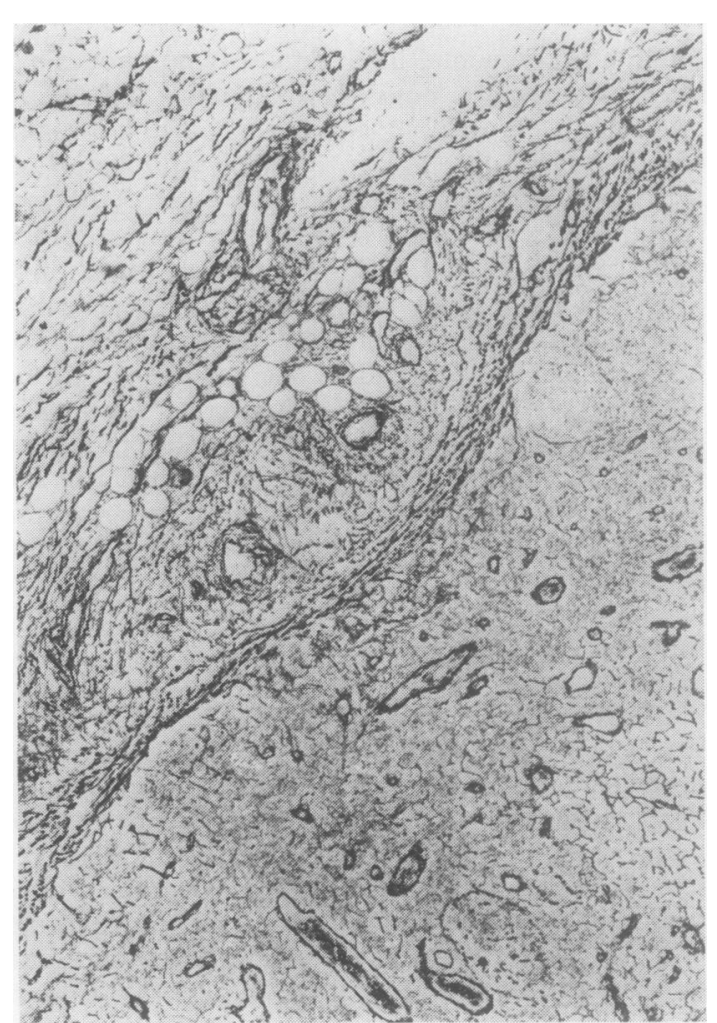

FIG. 2

Fig. 1 Case 1: early infarction of lymph node showing small thrombosed veins in node, and perinodal corona of polymorphonuclears $(H \& E \times 60)$.

Fig. 2 Section adjacent to Figure 1. Retention of reticulin in necrotic lymph node (silver reticulin $\times 60)$. 


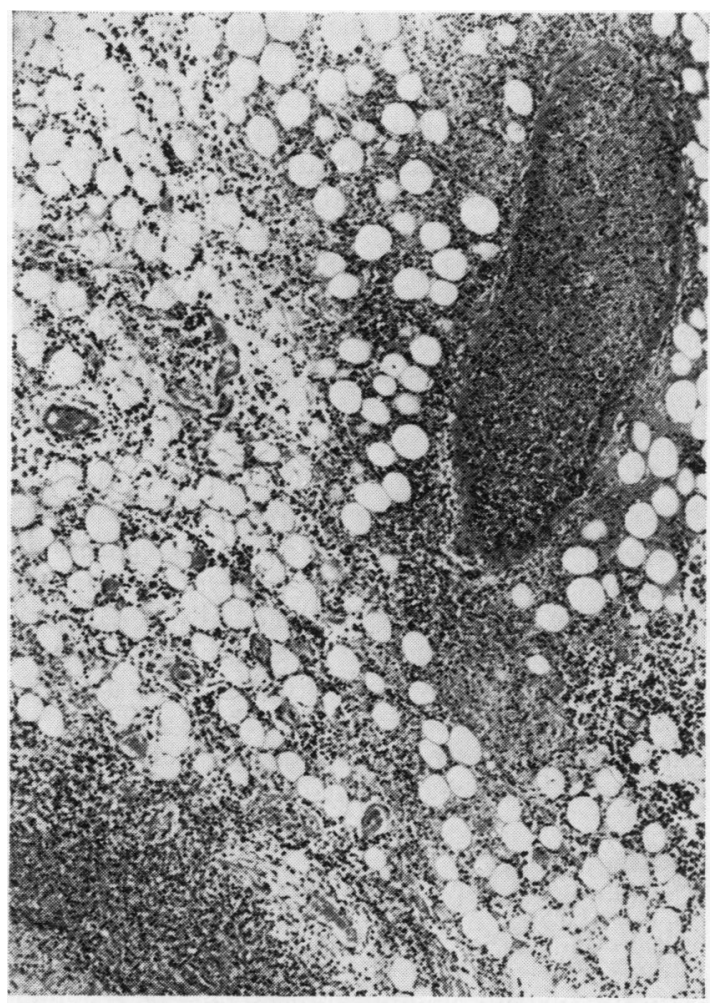

Fig. 3 Case 1: recent thrombosis of vein close to lymph node $(H \& E \times 60)$.

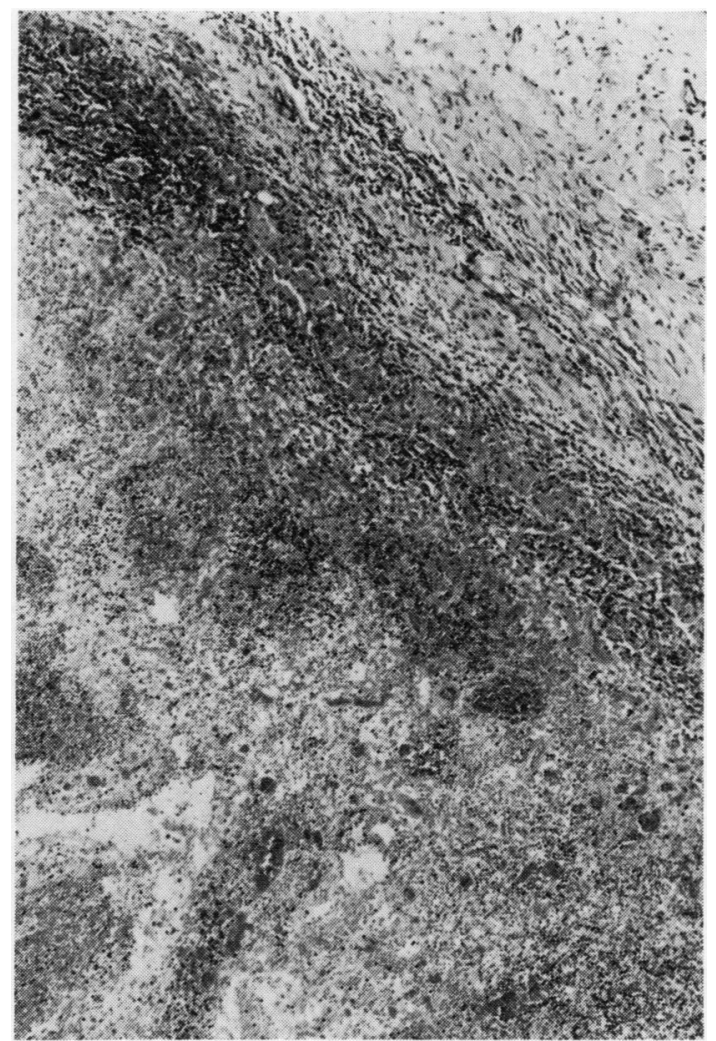

Fig. 4 Case 2: lymph node infarct at 16 days. Foci of lymphocytes survive beneath marginal sinus. Perinodal mononuclear infiltrate $(H \& E \times 60)$.

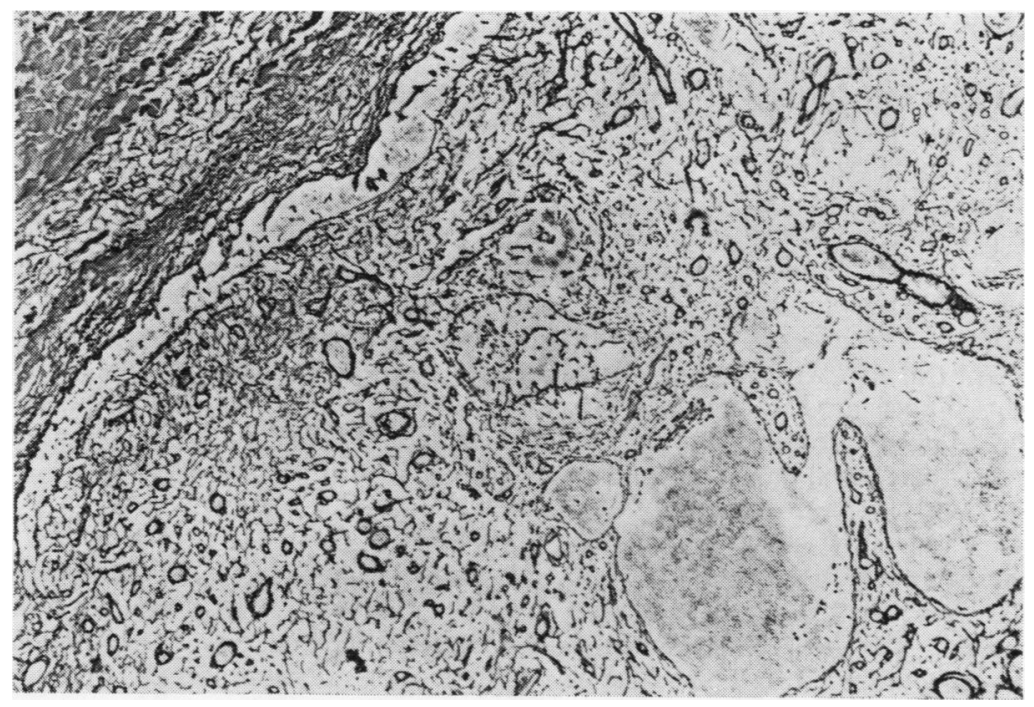

Fig. 5 Section adjacent to Figure 4. Focal reticulin condensation close to marginal sinus. Dilatation of deep lymph sinuses (silver reticulin $\times 60$ ). 


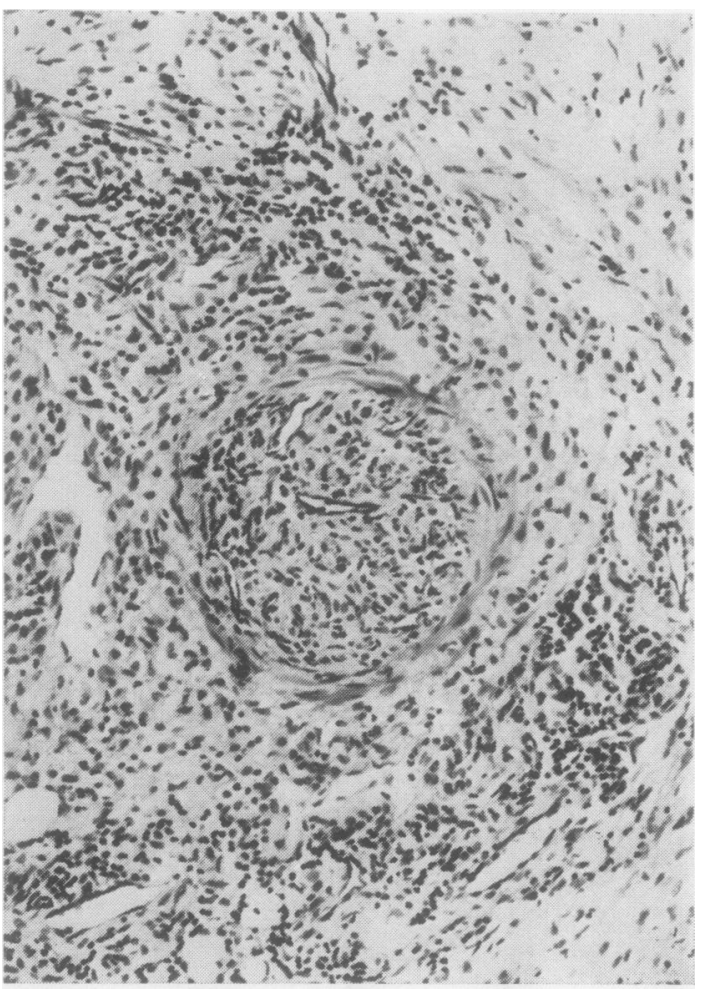

Fig. 6 Case 2: organizing thrombus in hilar vein $(H \& E \times 150)$.

node. No further similar symptoms have recurred in the two months since operation.

\section{Histopathology}

The lymph node from the axillary tail of breast (St. B.H. S.H. 513/72), $0.8 \mathrm{~cm}$ long, exhibited whitish yellow discoloration of its cut surface. Miscroscopy showed extensive necrosis of the node. Only sparse foci of lymphoid cells remained peripherally beneath the marginal sinus (Fig. 4) and deeply around small intranodal arteries and veins. The marginal sinus itself was intact but contained numerous degenerate sinus-lining histiocytes and a patchy lymph coagulum. Within the necrotic areas of the node there was extensive fibrin exudation, thrombosis of the intranodal veins, and necrosis of their walls. Despite the widespread nature of the necroses the reticulin architecture of the central part of the node was retained (Fig. 5). However, the Gordon and Sweet's preparations did show dilatation of the deep lymphatic sinuses and an accentuated reticulin network in the lymphoid tissue immediately beneath the marginal sinus. This peripheral reticulin change was accompanied by increased vascularity of the superficial cortex of the lymph node.

The capsule of the node was thickened, fibrous, and possessed prominent blood vessels. The perinodal connective tissue, particularly in the hilar region, contained a moderate inflammatory exudate, comprising lymphocytes, plasma cells, histiocytes, a few eosinophils, and fibroblasts and newly formed capillaries. A mononuclear exudate surrounded many extranodal veins, and a vein in the hilum was occluded by an organizing thrombus (Fig. 6).

\section{CASE 3}

A 33-year-old woman presented with an eight-day history of a painful lump in the axillary tail of the left breast. Six years earlier diabetes mellitus had been diagnosed at the time of delivery of a stillborn infant. The lesion in the axillary tail was diagnosed clinically as a fibroadenoma, and 17 days after its discovery was excised under local anaesthesia. When last seen 13 years afterwards diabetes mellitus was satisfactorilly controlled by insulin and there had been no recurrence of the axillary lesion.

\section{Histopathology}

The lymph node from the axillary tail of the breast (St. B.H. S.H. 3261/56) was $0 \cdot 6 \mathrm{~cm}$ long. Its cut surface was grey with reddish-brown mottling. Miscroscopically its appearances closely resembled those seen in case 2 . The extensive necrosis of the node, sparing only an incomplete narrow rim of peripheral cortical tissue, the preservation of the reticulin architecture in the necroses, and the extensive thrombosis of intranodal veins were all as described in the preceding case. Dilatation of the central lymph sinuses was, however, much less pronounced.

In this case the condensation of the reticulin network and vascularity of the peripheral lymphoid tissue were accompanied in many areas by vascular trabecular anastomoses across the marginal sinus. The appearances suggested well developed communications between the vessels in the periphery of the lymph node and those in the vascular fibrous capsule and the perinodal connective tissue. In the perinodal areolar tissue were numerous lymphocytes, plasma cells, eosinophils, and histiocytes. Much of this leucocytic infiltrate cuffed small veins, but thrombosis was not found in the few large extranodal vessels that were included in the biopsy.

\section{CASE 4}

A 53-year-old man was admitted as an emergency with a presumptive diagnosis of a strangulated left femoral and an uncomplicated direct left inguinal hernia. An increasingly tender lump in the left groin 
had been noted for about one week. Diabetes mellitus, necessitating diet and tolbutamide therapy had been diagnosed six years earlier. He was also hypertensive (BP 190/105 mm Hg). Examination showed a direct inguinal hernia and enlarged tender inguinal lymph nodes. A focus of infection in the drainage area of the left inguinal lymph nodes was not detected. At herniorrhaphy, at least two weeks after the onset of pain, the most enlarged inguinal lymph node was excised. Aerobic and anaerobic cultures of the node were sterile, and organisms were not seen in Gram and Ziehl-Neelsen stains of smears from the node. No further episodes attributable to infarction of lymph nodes occurred, but five years later he died after repeated episodes of congestive cardiac failure associated with left bundle branch block. Postmortem examination was not performed.

\section{Histopathology}

A single enlarged inguinal lymph node (St. B.H. S.H. $2838 / 61), 2.0 \mathrm{~cm}$ long, showed central yellow discoloration and softening. Microscopically, as in the preceding three cases, there was extensive central necrosis of the node with ghost-like remnants of lymphoid cells, numerous thrombosed and necrotic venous channels, and a preserved reticulin architecture. Only a small cap of peripheral lymphoid tissue (Fig. 7), including in this instance an intact lymphoid follicle with a germinal centre and a narrow rim of fibroblasts and lymphoid cells around a cortical artery, remained viable.

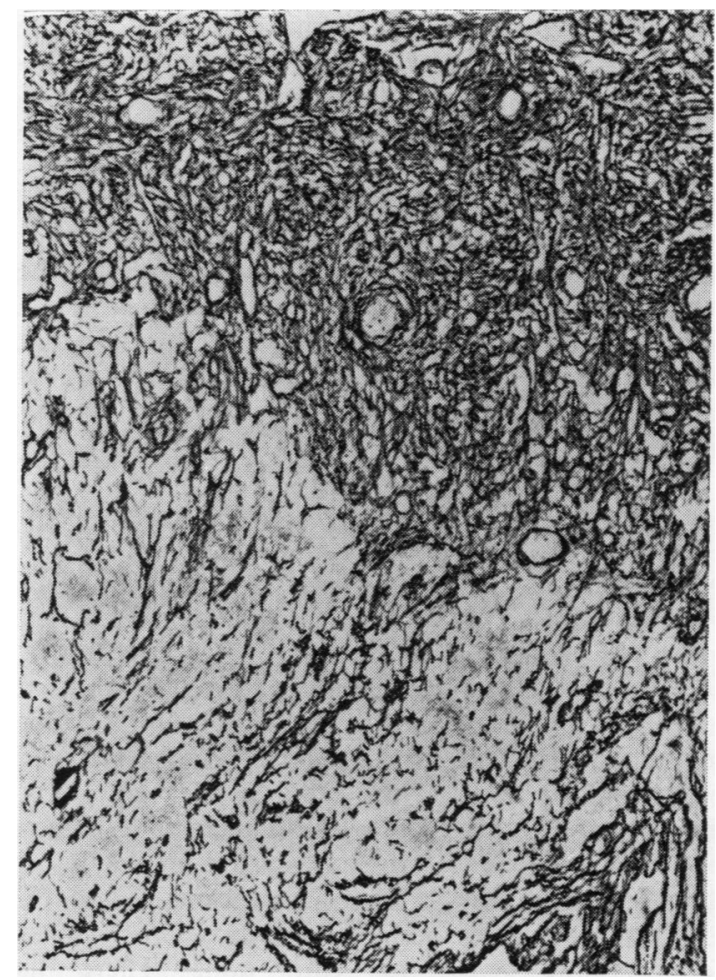

Fig. 8 Case 4: dense reticulin of granulation tissue extending across distorted marginal sinus (top) to necrosis (bottom) (Silver reticulin $\times 60$ ).

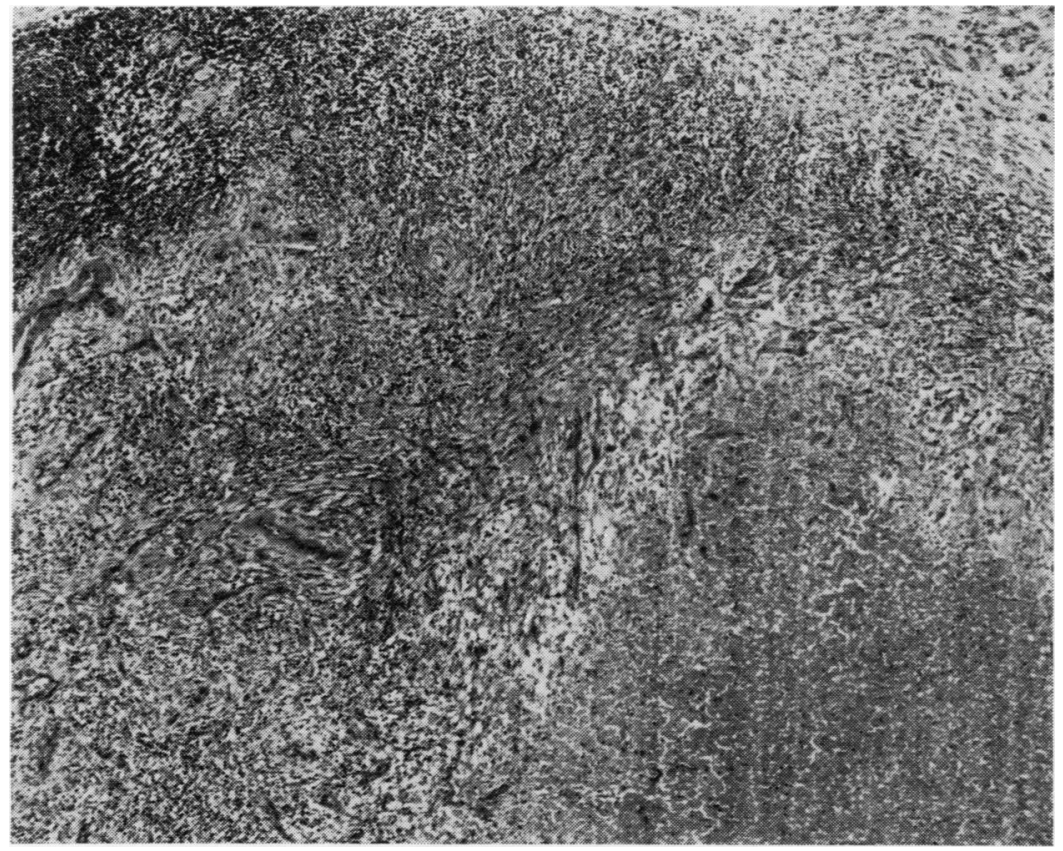

Fig. 7 Case 4: infarct (bottom right) bounded by granulation tissue, and cap of surviving lymphoid tissue (upper left $)(H \& E \times 35)$. 
Closely enveloping the necrotic area, and crossing the marginal sinus was a band of maturing granulation tissue (Fig. 8) comprising numerous fibroblasts, capillaries, and a mixed inflammatory infiltrate of polymorphonuclears, lymphocytes, and histiocytes. Neither giant cells nor epithelioid granulomata were, however, present. Venous thrombosis was not found in the perinodal tissue but several of the extranodal lymphatic vessels were occluded by a fibroblastic thickening of the intima. An adjacent muscular artery, though not thrombosed, exhibited luminal reduction associated with foamy histiocytes in the intima.

\section{CASE 5}

A 54-year-old woman with a 25-year history of varicose veins complained of a swelling in the left groin. The swelling had appeared one year before, accompanied by a tight feeling in the groin, about a month after both saphenous veins had been tied close to the sapheno-femoral junctions. Years previously bilateral stripping of the long saphenous veins, ligations and injection of sclerosing agents had been performed. On this occasion a provisional clinical diagnosis of a femoral hernia was made, but on exploration a $5 \mathrm{~cm}$-long fibrous-walled cyst was found among the inguinal lymph nodes. There was no sign of a femoral hernia.

\section{Histopathology}

Adjacent to the cyst were several pinkish inguinal lymph nodes (St. B.H. S.H. 1291/72), up to $2 \cdot 2 \mathrm{~cm}$ long. Microscopically the cyst proved to be necrotic lymphoid tissue surrounded by collagenous, acellular fibrous tissue. It seems likely that this structure represented a former lymph node but its internal architecture was almost totally lost. The appearances of the remaining nodes, however, were illuminating (Fig. 9). The lymphoid tissue of the surviving inguinal lymph noles was restricted to peripheral islands of lymphoid nodules lacking germinal centres, and scattered perivascular lymphoid aggregates encircled by prominent lymph sinuses. The marginal sinuses were incomplete. They were particularly discontinuous and distorted between the lymphoid nodules, at which point fibrous and vascular trabeculae passed from the fibrosed perinodal tissue to the medullary and hilar region of the nodes. Both medullae and hila of the nodes were bare of lymphoid and plasma cells. They were occupied by anastomosing lymphatic vessels and veins, many of which were occluded by partially recanalized thrombi. Further vascular abnormalities within the nodes were plexiform areas of recanalization of the marginal and central lymph sinuses and haemosiderin encrustation of the fibrotic walls of small arteries in the cortical lymphoid tissue. Many veins in the perinodal areolar tissue contained old, partially recanalized, occlusive thrombi.

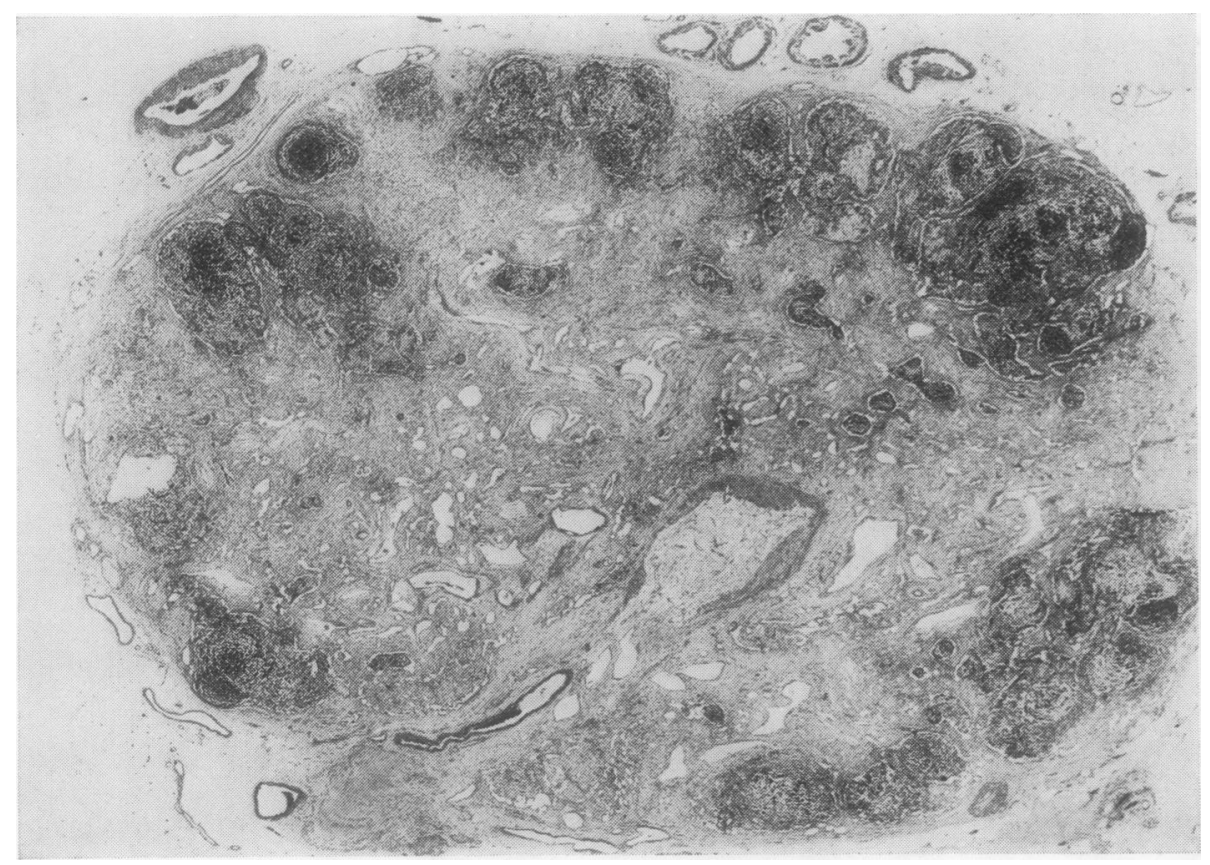

Fig. 9 Case 5: peripheral islands of lymphoid tissue around central anastomosing lymph sinuses and recanalizing thrombosed hilar vein $(H \& E \times 10)$. 


\section{Discussion}

Despite the challenge implicit in Holman and Self's (1938) provocative statement that infarction of lymph nodes in man 'is a rarity, if it ever occurs', we have been unable to trace any morphological description of changes that have been ascribed to infarction in previously normal lymph nodes. However, infarction of lymphomatous or metastatic neoplasms in lymph nodes is well known. Such necrosis of neoplasms may be sufficiently extensive as to mask the primary pathology. Several cases in our material apart from the five reported here, though not recognized with confidence when first seen, were found on review to be examples of infarcted neoplasms. Reticulin stains of the necrotic tissue proved particularly useful in the distinction of such cases.

The absence of granulomatous inflammation readily distinguishes the necrosis in the five cases from that seen in tuberculosis, and various fungal and viral infections. Both inguinal lesions lacked the brisk cellular infiltration of the necrosis, and the dense plasma cell accumulation and endarteritis that we have seen in a case of recently acquired syphilitic lymphadenitis. Furthermore the lesions described here do not resemble the generally focal necroses seen in the lymphadenopathies of hypersensitivity diseases involving small vessels, drug-induced hypersensitivity reactions (Schwartz, 1966; Krasznai and Szegedi, 1969), the Shwartzman phenomenon in lymph nodes (Koplik, 1937), or the larger haemorrhagic lesions resembling infarcts in acute suppurative lymphadenitis (Lennert, 1961).

The human lymph nodes considered here show striking resemblances to lymph nodes subjected to experimental infarction. After ligation of the entire arterial and venous vasculature of the popliteal lymph node of rabbits Osogoe and Courtice (1968) found at six hours a loss of cortical lymphocytes, and by 24 hours more widespread necrosis of the lymphoid tissue, with only a narrow rind of surviving lymphoid tissue close to the marginal and medullary sinuses. Occlusion of both blood vascular and lymphatic vessels led to a more rapid and extensive necrosis of the lymphoid cells, leaving an incomplete and narrow rim of surviving lymphoid tissue immediately deep to the marginal sinus. Devascularized autografts of lymph nodes in dogs rapidly necrosed, and in the first few days after operation showed such a brisk inflammatory infiltrate that infection was suspected (Holman and Self, 1938). Months later such nodes in dogs were reduced to fibrous nubbins (Tilak and Howard, 1965; Kister et al, 1965). Preservation of the lymphatic vessels appears to mitigate the effect upon the lymph nodes of blood vascular occlusion (Holman and Self, 1938) and to facilitate nodal regeneration after infarction (Osogoe and Courtice, 1968). It is interesting, in view of the preservation of the reticulin architecture of the freshly infarcted human lymph nodes, that regeneration of the lymphoid tissue occurred in the lymph nodes after arterial and venous occlusion in rabbits within 14 days (Osogoe and Courtice, 1968), and to a lesser extent at six months in dogs (Tilak and Howard, 1964).

We feel that the microscopic findings in the five human cases detailed above present distinctive appearances and an orderly chronological sequence. In the early stages there is a selective necrosis of the lymphoid cells furthest from their blood supply. At this time the reticulin framework of the node is preserved in most instances. The inflammatory events in the perinodal connective tissue are remarkably similar, both in morphology and time course, to those seen around human myocardial infarcts (Mallory, White, and Salcedo-Salgar, 1939). The heavy polymorphonuclear leucocytic infiltrate at three days was largely confined to the perinodal connective tissue, in which respect it differs fundamentally from the polymorphonuclear exudate of suppurative lymphadenitis. By the third week the polymorphonuclear leucocytes are increasingly replaced by mononuclear cells, and a zone of vascular and maturing granulation tissue appears in close apposition to the periphery of the necrosis. Finally, months after infarction in those nodes that are not irrevocably damaged, there is evidence of regeneration of lymphoid tissue. This regeneration, presumably effected by means of the lymphoid cell circulation, is not complete for the stigmata of granulation tissue, fibrosed necrotic blood vessels, recanalization of occluded lymph and blood vessels, and the disturbed architectural arrangement of the lymphoid tissue remain. The initial event leading to all five nodal infarcts appeared to be thrombosis of intranodal and hilar veins. In most instances the cause of the thrombosis was not apparent but it may have arisen in a superficial thrombophlebitis.

Aside from frank infarction, there have been few accounts of the effects of blood vascular lesions upon lymph nodes in man. A notable exception is the recent account by Haferkamp, Rosenau, and Lennert (1971) of the vascular transformation of lymph nodes that were drained by thrombosed veins. Possibly their cases differed from ours in that large veins were thrombosed, but it seems likely that the atrophy of lymphoid tissue they noted in two of their three cases was of ischaemic origin; irradiation of coexisting tumour was not responsible for this atrophy (Haferkamp, 1972, personal communication). Somewhat similar, but far less advanced, changes comprising 
vascular congestion and cortical depletion of lymphocytes were described by Mohiuddin (1965) in the mesenteric lymph nodes of rats shortly after experimental occlusion of the portal vein.

The reason for the apparent rarity of lymph node infarction may lie in the abundance of the vascular supply and in the well developed anastomoses. Nevertheless the classical studies of Calvert (1897) and Dabelow (1938-39) show that the major arterial supply and venous drainage of lymph nodes pass through the nodal hilum and extend radially to supply the medullary and cortical structures. Anastomoses through the capsule of lymph nodes were, however, found by Calvert and Dabelow and by Herman, Ohba, and Mellins (1969) to link the internal blood vessels of the nodes with those in the perinodal connective tissue. Additionally, it is likely that hilar anastomoses accompany the expansion of hilar connective tissue that develops in aging superficial lymph nodes (Denz, 1947). Further anastomoses, between the lymphatic and venous channels, have been postulated to explain the transfer from lymphatic to venous vessels of bacteria (Lancet, 1961), air (Pressman and Simon, 1961), and lymphangiography oil (Bron, Baum, and Abrams, 1963); more recently they have been shown in electron microscopic studies (Pressman, Dunn, and Burtz, 1967). Finally, the arterial supply, at least to the submandibular lymph nodes in many species, including man, is often not limited to a single named artery (Miyata, 1966). Thus the very abundance of the vasculature of lymph nodes may protect them against infarction. Possibly anastomoses may account for the sparing of the subcapsular tissues in those nodes which are infarcted. It is also possible that the regenerative capacity of infarcted nodes is related to their vascular architecture and the mobile nature of their lymphoid population.

We are grateful to $\mathrm{Mr} \mathrm{J}$. W. Miller and colleagues for the histological preparations and to $\mathrm{Mr}$ P. Crocker for the photomicrography. Our thanks are also due to surgical colleagues for access to the clinical records of the patients under their care.
References

Bron, K. M., Baum, S., and Abrams, H. L. (1963). Oil embolism in lymphangiography: incidence, manifestations, and mechanism. Radiology, 80, 194-202.

Calvert, W. J. (1897). The blood-vessels of the lymphatic gland. Anat. Anz., 13, 174-180.

Dabelow, A. (1938-39). Die Blutgefässversorgung der lymphatischen Organe. Anat. Anz., 87, Erg.-Heft., 179-224.

Denz, F. A. (1947). Age changes in lymph nodes. J. Path. Bact., 59, 575-591.

Haferkamp, O., Rosenau, W., and Lennert, K. (1971). Vascular transformation of lymph node sinuses due to venous obstruction. Arch. Path., 92, 81-83.

Herman, P. G., Ohba, S., and Mellins, H. Z. (1969). Blood microcirculation in the lymph node. Radiology, 92, 1073-1080.

Holman, R. L., and Self, E. B. (1938). The ability of lymph to maintain viability in 'devascularized' lymph nodes. Amer. J. Path., 14, 463-472.

Kister, S. J., Conklin, E. F., and Habif, D. V. (1965). Autotransplantation of lymph nodes in the dog. Surg. Forum., 16, 206208.

Koplik, L. H. (1937). Experimental production of hemorrhage and vascular lesions in lymph nodes: an extension of the Shwartzman phenomenon. J. exp. Med., 65, 287-302.

Krasznai, G., and Szegedi, G. (1969). Lymphadenopathie, verursacht durch Arzneimittel. Acta morph. Acad. Sci. hung., 17, 175-185.

Lancet (1961). Barrier function of lymph-glands (Leading article). Lancet 2, 1442.

Lennert, K. (1961). Lymphknoten. Diagnostik in Schnitt und Ausstrich. Bandteil A. Cytologie und Lymphadenitis (Lubarsch and Henke's Handbuch der speziellen pathologischen Anatomie und Histologie, Bd.I./Teil III), p. 163. Springer, Berlin.

Mallory, G. K., White, P. D., and Salcedo-Salgar, J. (1939). The speed of healing of myocardial infarction. Amer. Heart J., 18, 647671.

Miyata, T. (1966). Stereological studies on several ducts and vessels by injection method of acrylic resin. XVI. Arterial distribution of the submandibular lymph nodes in some mammals. Okajimas Folia anat. jap., 42, 265-280.

Mohiuddin, A. (1965). The acute effects of complete portal block on the jejunum and mesenteric lymph nodes of the white rat. West Afr. med. J., 14, 45-53.

Osogoe, B., and Courtice, F. C. (1968). The effects of occlusion of the blood supply to the popliteal lymph node of the rabbit on the cell and protein content of the lymph and on the histology of the node. Aust. J. exp. Biol. med. Sci., 46, 515-524.

Pressman, J. J., Dunn, R. F., and Burtz, M. (1967). Lymph node ultrastructure related to direct lymphaticovenous communication. Surg. Gynec. Obstet., 124, 963-973.

Pressman, J. J., and Simon, M. B. (1961). Experimental evidence of direct communications between lymph nodes and veins. Surg. Gynec. Obstet., 113, 537-541.

Schwartz, A. (1966). Uber allergische Lymphadenitis. Beitr. path. Anat., 134, 84-102.

Tilak, S. P., and Howard, J. M. (1964). The influence of the dual circulation on the viability of lymph nodes following interruption of their blood or lymphatic supply. Surg. Gynec. Obstet., $119,349-352$.

Tilak, S. P., and Howard, J. M. (1965). Regeneration and autotransplantation of lymph nodes. Ann. Surg., 161, 441-446. 